\title{
ANTIMICROBIAL ACTIVITY OF SOME OF THE SOUTH-INDIAN SPICES AGAINST SEROTYPES OF ESCHERICHIA COLI, SALMONELLA, LISTERIA MONOCYTOGENES AND AEROMONAS HYDROPHILA
}

\author{
M.N. Indu ${ }^{1}$; A.A.M. Hatha ${ }^{2 *}$; C. Abirosh ${ }^{1}$; U. Harsha ${ }^{1}$; G. Vivekanandan ${ }^{3}$ \\ ${ }^{1}$ School of Environmental Sciences, Mahatma Gandhi University, Gandhi Nagar, Kottayam, Kerala, India; ${ }^{2}$ Department of \\ Biology, School of Pure and Applied Sciences, The University of the South Pacific, Suva, Fiji; ${ }^{3}$ Laboratory of Histopathology, \\ Graduate School of Aquatic Biosciences, Tokyo University of Fisheries, Konan, Minato, Tokyo, Japan \\ Submitted: June 21, 2005; Returned to authors for corrections: January, 30, 2006; Approved: March 15, 2006
}

\begin{abstract}
Antibacterial activity of extracts of Allium sativum (garlic), Myristica fragrans (nutmeg), Zingiber officinale (ginger), Allium cepa (onion) and Piper nigrum (pepper) has been evaluated against 20 different serogroups of Escherichia coli, 8 serotypes of Salmonella, Listeria monocytogenes and Aeromonas hydrophila. Garlic extract showed excellent antibacterial activity against all the test organisms, except $L$. monocytogenes. Nutmeg showed good anti-listerial activity, although activity against E. coli and Salmonella were serotype dependent. Both garlic and nutmeg extracts were effective against $A$. hydrophila. Extracts of ginger showed inhibitory activity against two serogroups of E. coli: as O8 (enterotoxigenic E. coli) and O88 only. Extracts of onion and pepper did not show any antibacterial activity against the test organisms.
\end{abstract}

Key words: spices extract, antibacterial activity, Escherichia coli, Salmonella, Listeria monocytogenes, Aeromonas hydrophila

\section{INTRODUCTION}

Food borne pathogens such as diarrheagenic serotypes of Escherichia coli, Salmonella, Listeria monocytogenes and Aeromonas hydrophila are widely distributed in nature, causing considerable mortality and morbidity in the population. It has been reported that, worldwide, there are more than 1.3 billion cases of human salmonellosis annually, with three million deaths (19). Among the various diarrheagenic serotypes of E. coli, enterohemorrhagic E. coli $\mathrm{O} 157: \mathrm{H} 7$ is implicated in large number of food borne outbreaks in many parts of the world including developed nations (17). It is also reported that $E$. coli $\mathrm{O} 157: \mathrm{H} 7$ has low infective dose (8-9). Listeria monocytogenes has been isolated from various environments and is reported to cause $25 \%$ of all the deaths resulting from food-borne outbreaks in the United States annually (4). Aeromonas spp. represents a group of ubiquitous microorganisms in aquatic environments
(18). These bacteria have broad host range and have often been isolated from humans with diarrhoea (15).

Since the introduction of antibiotics there has been tremendous increase in the resistance of diverse bacterial pathogens $(6,11)$. This shift in susceptibility greatly affects our ability to successfully treat patients empirically. Plant derived products have been used for medicinal purposes for centuries. At present, it is estimated that about $80 \%$ of the world population rely on botanical preparations as medicines to meet their health needs. Herbs and spices are generally considered safe and proved to be effective against certain ailments (14). They are also extensively used, particularly, in many Asian, African and other countries. In recent years, in view of their beneficial effects, use of spices/herbs has been gradually increasing in developed countries also.

In the present study we have evaluated the antibacterial effect of the extracts of five widely used spices in South India such as Allium sativum (garlic), Myristica fragrans (nutmeg),

*Corresponding Author. Mailing address: Departmento of Biology, School of Pure and Applied Sciences, The University of the South Pacific, P.O. Box 1168, Suva. Fiji Islands. Tel.: (+679) 321-2550, Fax: (+679) 331-5601. E-mail: abdulla_m@usp.ac.fj - mohamedhatha@hotmail.com 
Zingiber officinale (ginger), Allium cepa (onion) and Piper nigrum (pepper) against 20 different serogroups of E. coli, 8 serotypes of Salmonella, L. monocytogenes and A. hydrophila. The inhibitory effect of these spices was compared with that of 5 antibiotics (chloramphenicol, ciprofloxacin, nalidixic acid, streptomycin and tetracyclin) and the results are discussed.

\section{MATERIALS AND METHODS}

\section{Microorganisms}

Twenty serogroups of E. coli, both pathogenic and nonpathogenic, were included in the present study. The pathogenic serogroups included O8 (enterotoxigenic E. coli, ETEC) and O157 (enterohemorrhagic E. coli, EHEC). The non pathogenic serogroups were O86, O30, O1, O69, O80, O88, O91, O51, O25, O116, O78, O22, O101, O33, O173, O104, O165, and O63. The strains were isolated from the Cochin estuary in a previous investigation (12) funded by Department of Science and Technology, Govt. of India.

Among Salmonella, the serotypes S. paratyphi, S. mgulani, S. bareily, S. enteritidis, S. senftenberg, S. typhimurium, S. weltevreden and $S$. worthington were included in the present study. While S. paratyphi, S. mgulani, S. typhimurium, S. weltevreden and $S$. senftenberg were isolated from seafood, S. worthington, S. bareily and S. enteritidis were isolated from chicken.

L. monocytogenes and A. hydrophila cultures were obtained from the culture collection of Institute of Microbial Technology (IMTECH), Chandigarh, India.

\section{Preparation of spices extracts}

The fresh spices were obtained from the local market. The spices were cleaned, descaled when necessary, and washed in sterile distilled water. In order to obtain the spice's extracts, about $100 \mathrm{~g}$ of each washed spice were crushed with mortar and pestle. The extracts were sieved through a fine mesh cloth and sterilized using a membrane filter (0.45-micron sterile filter). This extract was considered as the $100 \%$ concentration of the extract. The concentrations, $75 \%, 50 \%, 25 \%$ and $10 \%$ were made diluting the concentrated extract with appropriate volumes of sterile distilled water.

Garlic extract was made in a different way due to the difficulty to filter the crushed material. One hundred grams of the descaled and cleaned garlic were taken and surface sterilised using ethanol. The ethanol was allowed to evaporate in a sterile laminar flow chamber, and the garlic was homogenised aseptically using a sterile mortar and pestle. The extract was aseptically squeezed out using sterile cheesecloth.

\section{Antibacterial activity testing using agar well method (cup plate method)}

The selected strains of bacteria were inoculated into $10 \mathrm{~mL}$ of sterile nutrient broth, and incubated at $37^{\circ} \mathrm{C}$ for $16-18$ hours.
Using a sterile cotton swab, the nutrient broth cultures were swabbed on the surface of sterile nutrient agar plates. Agar wells were prepared with the help of sterilized cork borer with 10 $\mathrm{mm}$ diameter (23). Using a micropipette, 100 microlitres of different concentrations of spices extracts $(100 \%, 75 \%, 50 \%$, $25 \%$ and $10 \%$ ) were added to different wells in the plate. The plates were incubated in an upright position at $37^{\circ} \mathrm{C}$ for 24 hours. The diameter of inhibition zones was measured in $\mathrm{mm}$ and the results were recorded. The inhibition zones with diameter less than $12 \mathrm{~mm}$ were considered as having no antibacterial activity.

\section{Antibacterial sensitivity testing using filter paper method}

Filter paper discs of $7 \mathrm{~mm}$ diameter were prepared and sterilised. Using an ethanol dipped and flamed forceps, these discs were aseptically placed over nutrient agar plates seeded with the respective test microorganisms (23). One hundred microlitres of the various spices' extract (100\%) were aseptically transfered to these discs. The plates were incubated in an upright position at $37^{\circ} \mathrm{C}$ for 24 hours. The diameter of inhibition zones were measured in $\mathrm{mm}$ and the results were recorded. Inhibition zones with diameter less than $12 \mathrm{~mm}$ were considered as having no antibacterial activity. Diameters between 12 and $16 \mathrm{~mm}$ were considered moderately active, and these with $>16 \mathrm{~mm}$ were considered highly active.

\section{Antibiotic sensitivity testing}

The test microorganisms were also tested for their sensitivity against the antibiotics chloramphenicol (30 mcg), ciprofloxacin (5 mcg), nalidixic acid $(30 \mathrm{mcg})$, streptomycin $(10 \mathrm{mcg})$ and tetracycline (30 mcg) by the disk diffusion method (3).

The cultures were enriched in sterile nutrient broth for 6-8 hours at $37^{\circ} \mathrm{C}$. Using sterile cotton swabs, the cultures were aseptically swabbed on the surface of sterile Mueller-Hinton Agar (MHA) plates. Using an ethanol dipped and flamed forceps, the antibiotic discs were aseptically placed over the seeded MHA plates sufficiently separated from each other to avoid overlapping of the inhibition zones. The plates were incubated at $37^{\circ} \mathrm{C}$ for 24 hours and the diameter of the inhibition zones was measured in $\mathrm{mm}$. All the media used in the present investigation were obtained from Hi-media Laboratories Ltd., Mumbai, India.

\section{RESULTS AND DISCUSSION}

Among the five spices tested, three (garlic, nutmeg and ginger) showed antibacterial activity. The result of the antibacterial activity against serogroups of $E$. coli is given in Table 1.

Garlic extract showed excellent antibacterial activity at all concentrations $(100 \%, 75 \%, 50 \%$ and $25 \%)$ to all serogroups of E. coli tested in the present investigation, and the activity was a linear function of concentration. Different serogroups 
Table 1. Antibacterial activity of different concentrations of garlic, nutmeg and ginger extracts on serogroups of Escherichia coli by agar well method.

\begin{tabular}{|c|c|c|c|c|c|c|c|c|c|c|c|c|c|c|c|}
\hline \multirow{3}{*}{$\begin{array}{c}\text { E. coli } \\
\text { Serogroups }\end{array}$} & \multicolumn{15}{|c|}{ Diameter of inhibition zone (in $\mathrm{mm}$ ) against various concentrations of spices extract } \\
\hline & \multicolumn{5}{|c|}{ Garlic extract } & \multicolumn{5}{|c|}{ Nutmeg extract } & \multicolumn{5}{|c|}{ Ginger extract } \\
\hline & $100 \%$ & $75 \%$ & $50 \%$ & $25 \%$ & $10 \%$ & $100 \%$ & $75 \%$ & $50 \%$ & $25 \%$ & $10 \%$ & $100 \%$ & $75 \%$ & $50 \%$ & $25 \%$ & $10 \%$ \\
\hline O86 & 20 & 15 & 11 & 0 & 0 & 13 & 10 & 0 & 0 & 0 & 0 & 0 & 0 & 0 & 0 \\
\hline $\mathrm{O} 30$ & 28 & 21 & 16 & 10 & 0 & 14 & 11 & 0 & 0 & 0 & 0 & 0 & 0 & 0 & 0 \\
\hline $\mathrm{O} 1$ & 18 & 14 & 10 & 0 & 0 & 13 & 12 & 0 & 0 & 0 & 0 & 0 & 0 & 0 & 0 \\
\hline O69 & 25 & 19 & 15 & 9 & 0 & 15 & 14 & 0 & 0 & 0 & 0 & 0 & 0 & 0 & 0 \\
\hline O80 & 27 & 20 & 16 & 10 & 0 & 15 & 11 & 0 & 0 & 0 & 0 & 0 & 0 & 0 & 0 \\
\hline O88 & 26 & 21 & 15 & 8 & 0 & 17 & 11 & 0 & 0 & 0 & 18 & 13 & 0 & 0 & 0 \\
\hline O157* & 25 & 19 & 14 & 9 & 0 & 16 & 14 & 10 & 0 & 0 & 0 & 0 & 0 & 0 & 0 \\
\hline O91 & 25 & 20 & 14 & 10 & 0 & 0 & 0 & 0 & 0 & 0 & 0 & 0 & 0 & 0 & 0 \\
\hline O51 & 29 & 22 & 17 & 11 & 0 & 13 & 0 & 0 & 0 & 0 & 0 & 0 & 0 & 0 & 0 \\
\hline $\mathrm{O} 25$ & 30 & 24 & 18 & 13 & 0 & 14 & 0 & 0 & 0 & 0 & 0 & 0 & 0 & 0 & 0 \\
\hline O116 & 26 & 19 & 14 & 8 & 0 & 13 & 10 & 0 & 0 & 0 & 0 & 0 & 0 & 0 & 0 \\
\hline $\mathrm{O} 78$ & 25 & 20 & 13 & 9 & 0 & 10 & 0 & 0 & 0 & 0 & 0 & 0 & 0 & 0 & 0 \\
\hline $\mathrm{O} 22$ & 30 & 22 & 17 & 11 & 0 & 0 & 0 & 0 & 0 & 0 & 0 & 0 & 0 & 0 & 0 \\
\hline O101 & 28 & 21 & 15 & 10 & 0 & 10 & 8 & 0 & 0 & 0 & 0 & 0 & 0 & 0 & 0 \\
\hline O33 & 25 & 18 & 11 & 0 & 0 & 12 & 10 & 0 & 0 & 0 & 0 & 0 & 0 & 0 & 0 \\
\hline O173 & 27 & 22 & 14 & 8 & 0 & 18 & 16 & 12 & 0 & 0 & 0 & 0 & 0 & 0 & 0 \\
\hline O104 & 24 & 18 & 11 & 0 & 0 & 19 & 16 & 14 & 10 & 0 & 0 & 0 & 0 & 0 & 0 \\
\hline O165 & 24 & 19 & 10 & 0 & 0 & 15 & 10 & 0 & 0 & 0 & 0 & 0 & 0 & 0 & 0 \\
\hline O $8 * *$ & 24 & 18 & 12 & 0 & 0 & 0 & 0 & 0 & 0 & 0 & 10 & 0 & 0 & 0 & 0 \\
\hline O63 & 25 & 20 & 14 & 9 & 0 & 0 & 0 & 0 & 0 & 0 & 0 & 0 & 0 & 0 & 0 \\
\hline
\end{tabular}

*Enterohemorrhagic E. coli, **Enterotoxigenic E. coli.

responded differently to the garlic extract at different concentrations. At $100 \%$ concentration E. coli serogroup O1 was least sensitive $(18 \mathrm{~mm})$ and serogroup $\mathrm{O} 22$ and $\mathrm{O} 25$ were more sensitive $(30 \mathrm{~mm})$. Both enterohemorrhagic E. coli (EHEC, serogroup O157) and enterotoxigenic E. coli (ETEC, serogroup O8) were highly sensitive to garlic extract.

Table 2 represents the antibacterial activity of the spices extracts against different serotypes of Salmonella, Listeria monocytogenes and Aeromonas hydrophila. Garlic extract showed high antibacterial activity against Salmonella serotypes and A. hydrophila at $100 \%$ and $75 \%$ concentrations. Fifty percent concentration of the extract also showed moderate antibacterial activity against these strains. However, garlic extract was unable to inhibit the growth of L. monocytogenes at all concentrations. Different serotypes of Salmonella responded differently to the garlic extract. Highest inhibition was noticed against $S$. bareily.

The results agree with observations of previous researchers $(1,7,10,16,21)$. Antibacterial activity of garlic powder on $E$. coli O157:H7 was also reported (20). However, garlic extract did not show any inhibitory effect on the growth of $L$. monocytogenes. Our results were also comparable to those of other authors $(16,26)$, who had reported reduced activity of garlic extract on $L$. monocytogenes, suggesting that Gram positive organisms may be better equipped naturally to prevent the action of garlic extract.

The antibacterial activity of garlic is reported to be due to the action of allicin or diallyl thiosulphinic acid or diallyl disulphide (2). It is postulated that the antibacterial and antifungal properties of garlic juice are due to the inhibition of succinic dehydrogenase via the inactivation of thiol group. Our results revealed differences in the sensitivity of different serogroups of $E$. coli to garlic extract, suggesting that mechanisms of resistance are developing in this organism. Garlic can be used as a potent inhibitor of food pathogens. Use of garlic would increase the shelf life and decrease the possibilities of food poisoning and spoilage in processed foods.

Results of the antibacterial effect of nutmeg (Myristica fragrans) extract against 20 serogroups of $E$. coli revealed that most of them were sensitive to the extract at $100 \%$ and $75 \%$ concentrations (Table 1). At 10\% concentration, the extract did 
M.N. Indu et al.

Table 2. Antibacterial activity of different concentrations of garlic, nutmeg and ginger extracts on various serotypes of Salmonella, Listeria monocytogenes and Aeromonas hydrophila by agar well method.

\begin{tabular}{|c|c|c|c|c|c|c|c|c|c|c|c|c|c|c|c|}
\hline \multirow{3}{*}{$\begin{array}{l}\text { Pathogenic } \\
\text { Bacteria }\end{array}$} & \multicolumn{15}{|c|}{ Diameter of inhibition zone (in $\mathrm{mm}$ ) against various concentrations of spices extract } \\
\hline & \multicolumn{5}{|c|}{ Garlic extract } & \multicolumn{5}{|c|}{ Nutmeg extract } & \multicolumn{5}{|c|}{ Ginger extract } \\
\hline & $100 \%$ & $75 \%$ & $50 \%$ & $25 \%$ & $10 \%$ & $100 \%$ & $75 \%$ & $50 \%$ & $25 \%$ & $10 \%$ & $100 \%$ & $75 \%$ & $50 \%$ & $25 \%$ & $10 \%$ \\
\hline S. paratyphi & 27 & 20 & 14 & 9 & 0 & 0 & 0 & 0 & 0 & 0 & 0 & 0 & 0 & 0 & 0 \\
\hline S. mgulani & 28 & 22 & 17 & 11 & 0 & 0 & 0 & 0 & 0 & 0 & 0 & 0 & 0 & 0 & 0 \\
\hline S. bareily & 30 & 24 & 19 & 13 & 0 & 0 & 0 & 0 & 0 & 0 & 0 & 0 & 0 & 0 & 0 \\
\hline S. enteritidis & 29 & 22 & 17 & 10 & 0 & 0 & 0 & 0 & 0 & 0 & 0 & 0 & 0 & 0 & 0 \\
\hline S. senftenberg & 28 & 20 & 14 & 8 & 0 & 0 & 0 & 0 & 0 & 0 & 0 & 0 & 0 & 0 & 0 \\
\hline S. typhimurium & 25 & 17 & 12 & 0 & 0 & 0 & 0 & 0 & 0 & 0 & 0 & 0 & 0 & 0 & 0 \\
\hline S. weltevreden & 27 & 19 & 11 & 0 & 0 & 21 & 17 & 14 & 10 & 0 & 0 & 0 & 0 & 0 & 0 \\
\hline S. worthington & 28 & 21 & 18 & 12 & 0 & 20 & 15 & 12 & 0 & 0 & 0 & 0 & 0 & 0 & 0 \\
\hline A. hydrophila & 27 & 21 & 17 & 10 & 0 & 15 & 0 & 0 & 0 & 0 & 0 & 0 & 0 & 0 & 0 \\
\hline L. monocytogenes & 0 & 0 & 0 & 0 & 0 & 22 & 20 & 18 & 0 & 0 & 0 & 0 & 0 & 0 & 0 \\
\hline
\end{tabular}

not show any antibacterial activity. While the EHEC was sensitive to $100 \%$ concentration of the nutmeg extract, ETEC was not affected. The diameter of inhibition zone was maximum against $E$. coli serogroup O104. The growth of serogroups O22, O8, O63 and O91 was not inhibited by even $100 \%$ concentration of the nutmeg extract.

Table 2 represents antibacterial activity of nutmeg extract against serotypes of Salmonella, Aeromonas hydrophila and Listeria monocytogenes. When tested against eight serotypes of Salmonella, $S$. worthington and $S$. weltevreden were found to be sensitive. The inhibition zone obtained for both organisms was $20 \mathrm{~mm}$ and $21 \mathrm{~mm}$ respectively at $100 \%$ concentration, $15 \mathrm{~mm}$ and $17 \mathrm{~mm}$ at $75 \%$ concentration. The inhibitory effect against Aeromonas hydrophila was obtained at $100 \%$ concentration. Other concentrations did not show any activity. Listeria monocytogenes was found to be highly sensitive to nutmeg extract, although the growth of this organism was not affected by garlic extract. The inhibition zone obtained was high $(22 \mathrm{~mm})$ at $100 \%$ concentration, 20 $\mathrm{mm}$ at $75 \%$ and $18 \mathrm{~mm}$ at $50 \%$ concentration.

Results of the antibacterial activity of nutmeg extract showed interesting observations. Although the antibacterial activity of nutmeg extract on growth of $E$. coli serogroups was lower when compared to garlic extract, it had significant inhibitory effect on $L$. monocytogenes, the growth of which was otherwise unaffected by all other spices used in the present study. Except S. weltevreden and S. worthington, growth of other Salmonella serotypes was not
Table 3. Diameters of inhibition zones of antibiotics and spices extracts against Escherichia coli serogroups.

\begin{tabular}{ccccccccc}
\hline \multirow{2}{*}{$\begin{array}{c}E . \text { coli } \\
\text { serogroups }\end{array}$} & \multicolumn{6}{c}{ Diameter of inhibition zone $(\mathrm{mm})$} \\
\cline { 2 - 9 } & \multicolumn{6}{c}{ Antibiotics } & \multicolumn{4}{c}{ Spices extracts } \\
\cline { 2 - 9 } & Cf & C & T & S & Na & $\begin{array}{c}\text { Nutmeg } \\
(100 \%)\end{array}$ & $\begin{array}{c}\text { Garlic } \\
(100 \%)\end{array}$ & $\begin{array}{c}\text { Ginger } \\
(100 \%)\end{array}$ \\
\hline O86 & 27 & 28 & 16 & 15 & 21 & 13 & 20 & 0 \\
O30 & 0 & 26 & 19 & 13 & 0 & 14 & 28 & 0 \\
O1 & 20 & 29 & 11 & 14 & 0 & 13 & 18 & 0 \\
O69 & 26 & 28 & 21 & 12 & 22 & 15 & 25 & 0 \\
O80 & 17 & 26 & 7 & 14 & 0 & 15 & 27 & 0 \\
O88 & 28 & 29 & 11 & 15 & 22 & 17 & 26 & 18 \\
O157* & 25 & 22 & 8 & 9 & 21 & 16 & 25 & 0 \\
O91 & 26 & 25 & 21 & 14 & 24 & 0 & 25 & 0 \\
O51 & 21 & 29 & 10 & 0 & 12 & 13 & 29 & 0 \\
O25 & 25 & 25 & 16 & 13 & 22 & 14 & 30 & 0 \\
O116 & 19 & 31 & 18 & 18 & 0 & 13 & 26 & 0 \\
O78 & 24 & 28 & 13 & 13 & 22 & 10 & 25 & 0 \\
O22 & 25 & 27 & 20 & 14 & 18 & 0 & 30 & 0 \\
O101 & 0 & 26 & 11 & 13 & 0 & 10 & 28 & 0 \\
O33 & 22 & 26 & 19 & 13 & 18 & 12 & 25 & 0 \\
O173 & 28 & 28 & 17 & 15 & 22 & 18 & 27 & 0 \\
O104 & 25 & 29 & 20 & 13 & 22 & 19 & 24 & 0 \\
O165 & 23 & 24 & 22 & 14 & 24 & 15 & 24 & 0 \\
O8** & 25 & 27 & 22 & 14 & 24 & 0 & 24 & 10 \\
O63 & 0 & 28 & 10 & 13 & 0 & 0 & 25 & 0 \\
\hline
\end{tabular}

*Enterohemorrhagic E. coli (EHEC). **Enterotoxigenic E. coli (ETEC); Cf - Ciprofloxacin, C - Chloramphenicol, T - Tetracycline, S - Streptomycin, $\mathrm{Na}-$ Nalidixic acid. 
inhibited by the nutmeg extract. E. coli serogroups also showed variation in their sensitivity to nutmeg extract. The antililsterial activity of nutmeg extract is significant, as L. monocytogenes was otherwise not sensitive to any of the spices extracts used in present study. Considering the availability of nutmeg pods as an agricultural by-product in South India, efforts should be undertaken to extract the active component from the nutmeg pods for further use in medication. Literature on the antibacterial activity of Myristica fragrans is reduced, probably due to the limited distribution of this plant species.

Ginger extract was also found to have moderate antibacterial properties against $E$. coli serogroups $\mathrm{O} 8$ and O88. However, our results compare well with previous observations (5). Ginger extract did not show any antibacterial activity against all other serogroups of E. coli, Salmonella, L. monocytogenes and A. hydrophila. These results are contradictory to the observations of others authors $(22,24)$, who had reported moderate activity of ginger extract on $S$. paratyphi and S. enteritidis. Extracts of onion and pepper also did not show any antibacterial activity.

When tested by paper disc method, the antibacterial activity of the spices was less evident. Although garlic extract $(100 \%)$ maintained good antibacterial activity against all the test organisms except $L$. monocytogenes, nutmeg extract showed activity against $E$. coli serogroups O173, O104 and $O 165$. Nutmeg extract (100\%) showed activity against $S$. weltevreden, $S$. worthington, A. hydrophila and L. monocytogenes.

The results obtained for onion extract disagree with the observations of Srinivasan et al., 2001 (23), who reported moderate antibacterial activity of onion extract against $E$. coli, S. paratyphi and S. typhimurium. Good antibacterial activity of onion extract on the growth of S. enteritidis was also reported by Suresh et al., 2004 (24). In our study, the various concentrations of onion extract failed to inhibit the growth of all the test organisms. The differences may be due to a difference in the variety of the onion used in this study. Extracts of green pepper were found to be ineffective in controlling the growth of the various test organisms. Again, little literature on the antibacterial activity of Piper nigrum is available.

The diameter of the inhibition zone obtained against various spices at $100 \%$ concentration by agar well method was compared to those obtained against commonly used antibiotics (Tables 3 and 4). Garlic extract presented higher diameter of inhibition zones than ciprofloxacin, chloramphenicol, tetracycline, streptomycin and nalidixic acid. While $L$. monocytogenes was resistant against these antibiotics, nutmeg extract at $100 \%$ concentration had strong antilisterial activity, suggesting its possible use in treatment of infections caused by L. monocytogenes.
Natural products of plant origin have played significant role in the search for therapeutic drugs, such as quinine from Cinchona (14). Search for new antimcrobials is very important in recent times, considering the escalating levels of antibiotic resistance among pathogenic bacteria $(13,25)$. Enhanced animal husbandry practices have added further gravity to this problem. The results of this study are quite encouraging, considering the closeness of western ghats, a biodiversity hotspot in South India, to our institution.

\section{RESUMO}

\section{Atividade antimicrobiana de condimentos do sul da India sobre Escherichia coli, Salmonella, Listeria monocytogenes e Aeromonas hydrophila}

Avaliou-se a atividade antimicrobiana de extratos de alho (Allium sativum), noz-moscada (Mysritica frangrans), gengibre (Zingiber officinale) cebola (Allium cepa) e pimenta do reino (Piper nigrum) sobre 20 sorotipos de Escherichia coli, 8 sorotipos de Salmonella, Listeria monocytogenes e Aeromonas hydrophila. $\mathrm{O}$ alho apresentou atividade antimicrobiana excelente sobre todos os microrganismos testados, excepto $L$. monocytogenes. A noz-moscada apresentou boa atividade antilisteria, emboara atividade sobre E. coli e Salmonella tenha sido sorotipo-dependente. Tanto alho como noz-moscada foram eficientes contra A. hydrophila. O extrato de gengibre 
apresentou atividade inibitória sobre dois sorotipos de E. coli: 08 (enterotoxigenico) e 088 . Os extratos de cebola e pimenta do reino não apresentaram nenhuma atividade contra os microrganismos testados.

Palavras-chave: extrato de condimentos, atividade antibacteriana, Escherichia coli, Salmonella, Listeria monocytogenes, Aeromonas hydrophila

\section{REFERENCES}

1. Arora, D.S.; Kaur, J. Antimicrobial activity of spices. Int. J. Antimicrob. Agents, 12(3), 257-62, 1999.

2. Avato, P.; Tursil, E.; Vitali, C.; Miccolis, V.; Candido, V. Allylsulfide constituents of garlic volatile oil as antimicrobial agents. Phytomedicine, 7(3), 239-243, 2000.

3. Bauer, A.W.; Kirby, W.M.M.; Sherris, J.C.; Turck, M. Antibiotic susceptibility testing by standardized single disk method. Am. J. Clin. Pathol., 45, 493-496, 1966.

4. Centers for Disease Control and Prevention. Escherichia coli O157: H7 outbreak linked to commercially distributed dry-cured salamiWashington and California. Morb. Mortal. Wkly. Rep., 44, 157-160, 1995.

5. Chen, H.C.; Chang, M.D.; Chang, T.J. Antibacterial properties of some spice plants before and after heat treatment. Zhonghua Min Guo Wei sheng Wu Ji Mian Yi Xue Za Zhi., 18(3), 190-195, 1985.

6. Cohen, M.L. Epidemiology of drug resistance, implications for a post antimicrobial era. Science, 257, 1050-1055, 1992.

7. De, M.; Krishna De, A.; Banerjee, A.B. Antimicrobial screening of some Indian spices. Phytother. Res., 13(7), 616-618, 1999.

8. Doyle, M.P. Escherichia coli $\mathrm{O} 157: \mathrm{H} 7$ and its significance in foods. Int. J. Food Microbiol., 12, 289-302, 1991.

9. Doyle, M.P.; Zhao, T.; Meng, J.; Zhao, P. Escherichia coli O157:H7. In: Doyle, M.P.; Beuchat, L.R.; Montville, T.J. (eds). Food Microbiology: Fundamentals and Frontiers. American Society for Microbiology, Washington D.C., 1997, p.171-191.

10. Elnima, E.I.; Ahmed, S.A.; Mekkawi, A.G.; Mossa, J.S. The antimicrobial activity of garlic and onion extracts. Pharmazie, 38(11), 747-748, 1983.

11. Gold, S.G.; Moellering, R.C. Antimicrobial drug resistance. N. Engl. J. Med., 335, 1445-1453, 1996.
12. Hatha, A.A.M.; Abirosh Chandran, Mujeeb Rahiman, K.M. Prevalence of diarrhegenic serotypes of Escherichia coli and Salmonella in the Cochin estuary. Ind. J. Mar. Sci., 33(3), 72-77, 2004.

13. Hatha, A.A.M.; Lakshmanaperumalsamy, P. Antibiotic resistance of Salmonella strains from marketed fish and crustaceans. Lett. Appl. Microbiol., 24, 47-49, 1995.

14. Hora, S.L.; Nair, K.K. Pollution of streams and conservation of fisheries. Proc. Natl. Inst. Sci. India, 10, 147-166, 1944.

15. Janda, J.M.; Abbot, S.L. Evolving concepts regarding the genus Aeromonas: an expanding panorama of species, disease presentations and unanswered questions. Clin. Infect. Dis., 27, 332-344, 1998.

16. Kumar, M.; Berawal, J.S. Sensitivity of food pathogens to garlic (Allium sativum). J. Appl. Bacteriol., 84(2), 213-215, 1998.

17. Mead, P.S.; Slutsker, L.; Dietz, V.; McCaig, L.F.; Bresee, J.S.; Shapiro, C.; Griffin, P.M.; Tauxe, R.V. Food related illness and death in the United States. Emerg. Infect. Dis., 5, 607-625, 1999.

18. Monfort, P.; Baleux, B. Dynamics of Aeromonas hydrophila; Aeromonas sobria and Aeromonas caviae in sewage treatment pond. Appl. Environ. Microbiol., 56, 1999-2006, 1990.

19. Pang, T.; Bhutta, Z.A.; Finlay, B.B.; Altwegg, M. Typhiod fever and other salmonellosis: a continuing challenge. Trends Microbiol., 3, 253-255, 1995.

20. Sasaki, J.; Kita, T.; Ishita, K.; Uchisawa, H.; Matsue, H. Antibacterial activity of garlic powder against Escherichia coli O157. J. Nutr. Sci. Vitaminol., (Tokyo), 45(6), 785-790, 1999.

21. Shobana, S.; Naidu, K.A. Antioxidant activity of selected Indian spices. Prostaglandins Leukot. Essent. Fatty Acids, 62(2), 107-110, 2000.

22. Srinivasan, D.; Lakshmanaperumalsamy P. Antibacterial activity of some medicinal plants. Bull. Env. Sci., 11, 21-24, 1993.

23. Srinivasan, D.; Sangeetha Nathan, Suresh, T.; Lakshmanaperumalsamy, P. Antimicrobial activity of certain Indian medicinal plants used in folkloric medicine. J. Ethnopharmacol., 74, 217-220, 2001.

24. Suresh, T.; Hatha, A.M.; Srinivasan, D.; Srinivasan, S.; Lakshmanaperumalsamy, P. Salmonella cross contamination in retail chicken outlets and the efficacy of spice extracts on Salmonella enteritidis growth inhibition on various surfaces. Microbes Environ., 19(4), 152-157, 2004.

25. Suresh, T.; Srinivasan, D.; Hatha, A.A.M.; Lakshmanaperumalsamy, P. A study on the incidence, antibiotic resistance and survival of Salmonella and Escherichia coli isolated from broiler chicken retail outlets. Microbes Environ., 15(3), 173-181, 2000.

26. Thongson, C.; Davidson, P.M.; Mahakarnchanakul, W.; Weiss, J. Antimicrobial activity of ultrasound-assisted solvent-extracted spices. Lett. Appl. Microbiol., 39(5), 401-406, 2004. 